\title{
Older Women in Australia: Facing the Challenges of Dual Sensory Loss
}

\author{
Chyrisse Heine ${ }^{1}\left[\right.$, Cathy Honge Gong ${ }^{2,3, *}$, Susan Feldman ${ }^{4}$ and Colette Browning $2,5,6$ (D) \\ 1 School of Allied Health, Human Services \& Sport, College of Science, Health and Engineering, La Trobe \\ University, Bundoora, VIC 3086, Australia; c.heine@latrobe.edu.au \\ 2 Centre for Research on Ageing, Health and Wellbeing, Research School of Population Health, College of \\ Health and Medicine, Australian National University, Canberra, ACT 2617, Australia \\ 3 Australian Research Centre (ARC) Centre of Excellence in Population Ageing Research, Canberra, \\ ACT 2601, Australia \\ 4 Independent Researcher, 41 Tyrone Street, South Yarra, VIC 3141, Australia; Susan@myaddress.net.au \\ 5 School of Nursing and Healthcare Professions, Federation University, Mt Helen Campus, Ballarat, VIC 3353, \\ Australia; c.browning@federation.edu.au \\ 6 International Institute for Primary Health Care Research, Shenzhen 518000, China \\ * Correspondence: cathy.gong@anu.edu.au
}

Received: 6 December 2019; Accepted: 23 December 2019; Published: 30 December 2019

\begin{abstract}
With the increase in longevity, the number of women living into old age is rising and higher than that of men. Data was derived from the Melbourne Longitudinal Studies on Healthy Ageing Program, which included 533 women and 467 men aged 65 years and older, in Australia, over 10 years. Logistic regression modeling was used to investigate the prevalence of dual sensory loss and the unmet needs for vision and hearing devices in older women (compared to men) over time, as well as its impacts on self-reported general health, depression, perceived social activities, community service use and ageing in place. Results suggested that the prevalence of dual sensory loss increased for women from the age of 75 years and over. Dual sensory loss was higher for older women and men who were living alone, with government benefits as their main income source or were divorced, separated or widowed. Dual sensory loss had significant impacts on poor general health, perceived inadequate social activities and community service use for women and men and on depression for women only. Early identification of dual sensory loss is essential to minimize its effects, ensuring continued well-being for this population.
\end{abstract}

Keywords: older women; dual sensory loss; physical health; mental health; social health; well-being; quality of life; Australia

\section{Introduction}

As adults age, they often experience a number of health conditions, including deterioration in vision and hearing. According to the World Health Organization (WHO) [1], there are 253 million people worldwide with vision impairment and 36 million people classified as legally blind. Of the global population with vision impairment, eighty one percent are aged 50 years and over with this percentage increasing as the older adult population increases worldwide. Specifically, the prevalence of low vision amongst older adults (based on test measures) is $4.51 \%$ for $60-69$-year-olds, $11.41 \%$ for $70-79$-year-olds, $28.75 \%$ for $80-89$-year-olds and $39.49 \%$ for those 90 years and older [2]. There is also a high prevalence of people worldwide with disabling hearing loss (360 million people or $5.3 \%$ of the world's population) [3]. Hearing loss (as measured by self-report) is exacerbated as people grow older [4]) and approximately one-third of people with hearing loss are aged 65 years and over [5]. 
Dual sensory loss (DSL) is the combined loss of vision and hearing associated with the aging process [6]. DSL is also known as deafblindness and is a more disabling condition that just the combined effect of vision loss and hearing loss, since those with DSL are a heterogenous group consisting of people with various levels of vision and hearing loss, possible additional disabilities and varying medical aetiologies [7]. DSL is a prevalent disability in older adults. Whilst the absolute number of older adults with DSL is unknown, estimates vary from 3\% for those aged 60-69 years to $21.9 \%$ for those aged 80 years and over [8]. In an Australian study of older adults, it was reported that the prevalence of DSL increases steadily with age up to $26.8 \%$ for those adults aged 80 years and over [9]. Results of a Canadian Longitudinal Study on Aging using audiometry and visual acuity measures, suggested that in 2016, 1.5 million males aged 45-85 years had hearing loss, 1.8 million had vision loss and 570,000 had DSL. Prevalence increased from 8.7\% to 16.9\% between 2011 and 2016 [10]. Similar results have been obtained in other countries (for example, China) with the prevalence of DSL increasing with age [11].

Eye conditions that are prevalent in older adults are macular degeneration, diabetic retinopathy, cataract, glaucoma and retinitis pigmentosa, with macular degeneration as the leading cause in high-income countries [12]. Women have higher prevalence of moderate and severe vision impairment and blindness than men. Women are also more likely to report more functional difficulties than men as a result of visual impairment [13]. Common causes of hearing loss in older adults include presbycusis, impacted cerumen, chronic otitis media with effusion, noise-induced hearing loss and genetic factors [14]. According to Dammeyer, Rubella Syndrome and Down's Syndrome are the largest causes of congenital deafblindness amongst adults aged 18 years and over [15]. Cruikshanks et al. [16] investigated the 10 year cumulative incidence of hearing impairment and its associations with education, occupation and noise exposure history. Results of this study suggested that although the risk of hearing impairment was high for both men and women, women experienced a slightly later onset. Hearing sensitivity in men and women is associated with different factors. Poorer hearing sensitivity was associated with high triglyceride levels, high resting heart rate and history of smoking for men. For women, poor hearing sensitivity was associated with high body mass index, high resting heart rate, fast pulse wave velocity, and low Ankle-Arm Index suggestive of peripheral artery disease, putting women at risk of experiencing arterial disease such as stroke [17]. Faster hearing decline is associated with loneliness and being a widow(er) [18], which is a traumatic experience that occurs more frequently in older women than men [18].

With the ageing of populations, the prevalence rate of DSL is set to rise, especially since older adults (those aged 65 years and over) represent the fastest growing segment of the world's population. In 2010, the older population was 524 million and the World Health Organization [19] has estimated that the older adult population will increase to nearly 1.5 billion by 2050. According to the Australian Government Productivity Commission [20], by 2060, one in six Australians will be aged 75 years or more. By 2050, the number of older adults aged 85 years and over will quadruple from 0.4 million to 1.8 million [21]. There will also be a $25 \%$ rise in the number of centenarians living in Australia and older women outnumber older men, since they live longer. This finding is similar to other developed countries, for example, in the U.S. [22]. In 2017, whilst approximately half of all people aged 65-74 years (51\%) and $75-84$ years (54\%) were women, in the older age group (85 years and over), $63 \%$ of people were women [23]. Of this population group, many older women are widowed and living alone [24]. Furthermore, the Australian Bureau of Statistics (ABS) reported that over the past two decades, the number of people aged 100 years and over increased by $271 \%$ - of which, there were almost four times as many women than men [25]. Sensory devices are often used to improve the sensory capacity. In Australia, eye check and glasses are often used by older Australians with support from Medicare insurance. However, hearing tests and hearing aids are not as well supported by Medicare and are thus less frequently used by older Australians than glasses. In addition, visual aids are not always helpful for people with severe vision loss, and many older adults with hearing loss or DSL do not successfully use amplification or other assistive listening devices successfully to improve their hearing [26]. 
DSL is a debilitating condition that interferes with communication $[27,28]$, particularly since non-verbal cues such as lipreading are not visible. DSL also inhibits independence, limits one's activities, restricts participation in society and influences well-being [29-32]. In a systematic review conducted by Heine and Browning [33], it was found that a range of comorbidities (such as depression and decreased independence) are associated with DSL in older adults. Specifically, a study by Heine, Gong and Browning [11] conducted in China revealed that DSL (as measured by self-report) was significantly and positively associated with advancing age and difficulty in daily living activities. Based on a sample of 21,241 participants aged 45 to 89 years who participated in the Canadian Longitudinal Study on Aging, it was concluded that DSL was independently associated with reduced social network diversity and reduced social participation [34]. These results have been confirmed by Viljanen and colleagues who conducted a cross-sectional study in eleven European countries to evaluate whether sensory difficulties were associated with social inactivity in older adults. Results of this study suggested that sensory difficulties were associated with social inactivity although social inactivity was attenuated by health and socioeconomic indicators [35]. Outcomes of this study also suggested that people with DSL experienced high levels of depression and less life satisfaction [11]. Examining vision loss, hearing loss and DSL separately, Tseng and colleagues conducted a systematic review of the literature and found that increased severity of sensory loss resulted in lower quality of life. Quality of life was also worse for those with DSL as compared to people with vision or hearing loss individually [36]. Older women's increased longevity [25] possibly contributes to their vulnerability for developing DSL. Older women are not only affected by DSL but also by a number of health, social and economic changes as they age [37]. Older women are more socially and economically vulnerable than older men and more likely to be widowed, divorced, or separated, to depend on government benefits, to be caregivers, or to live alone. Although the majority of older women take measures to prepare for their future care needs, many miss key steps recommended for their future potential well-being $[38,39]$. Despite coping with difficult circumstances, illness or compromised health (such as being recently widowed, disabled or physically frail), women can remain active and satisfy their needs and aspirations more easily than men $[39,40]$. Women are, however, potentially disproportionally affected by DSL which may limit their ability to maintain relationships with others and interact in society.

In Australia, 73\% of adults aged 65 years and over rate their health as good or better, with the majority living in their own homes with good access to health services [23,25]. However, aging populations are often associated with increases in disability and burden of disease [23]. Managing illness and disability in old age is an important contributor to quality of life and well-being. The aims of this study were to investigate the health inequalities of DSL amongst older women (the most disadvantaged group) by comparing older women to older men. Specifically, this study aimed to:

(1) Describe the prevalence and trajectories of DSL and unmet needs for sensory aids over time and its associated demographic factors and socioeconomic status, in a representative sample of older women (in comparison to men);

(2) Evaluate the associations between DSL and the following variables in women (in comparison to men): living conditions, physical health, mental health, participation in social activities and use of community services at baseline;

(3) Estimate the baseline predictors (including DSL) for ageing in place for both women and men during the whole survey period.

We hypothesized that: (1) DSL will increase with age and its prevalence and related unmet needs will be influenced by socioeconomic status; (2) older women are more likely to live alone and have DSL and other health conditions; and (3) DSL will have a significant influence on physical, mental and social health but affect women differently than men. 


\section{Materials and Methods}

\subsection{Data}

The presented analyses utilize data obtained from the Melbourne Longitudinal Studies on Healthy Ageing (MELSHA) Program, which is a 16 year longitudinal study focusing on the physical and mental health of older individuals [41]. The state electoral roll was used to develop a clustered sample of 1422 potentially eligible participants (people aged 65 years and over, who speak English and reside in private dwellings in Metropolitan Melbourne, Australia). The survey did not include people who were living in non-private accommodation, those who could not speak basic English, or those who could not be interviewed for health reason. Excluding these 'out of scope' categories, the response rate for the initial interview was 70\%, yielding a base sample of 1000 people aged 65 years and over living in Melbourne private dwellings in year 1994 representative of older people in Melbourne at the time.

Over the 16 year period of the study, there were in total 9 waves of data collection, and respondents in the baseline survey were followed up biannually by telephone interviews and by mail in the intervening years. Face-to-face interviews were conducted at baseline and in Waves 7,8 and 9. Where respondents could not be contacted directly, the tracing procedures relied primarily on next of kin or other individuals volunteered by respondents as key contacts at the time of the baseline interviews. The death data in 2008 and residential care use data in 2006 were linked by resident with the MELSHA longitudinal survey data from 1994 to 2010 [42]. A full description of the cohort profile can be found in Browning and Kendig [41].

The 1994 baseline survey recorded detailed information about respondent's demographic and socioeconomic characteristics, housing, health status, health behaviours and functioning, medical conditions, care needs and service use. As detailed in Browning and Kendig [41], follow-up survey rounds collected information on a summary set of priority outcome variables. Among the older people who had died during the survey period, most were found to have either died at home or in hospital (deaths after entry to residential care were more difficult to identify). A minority of those who were identified as having left their baseline homes were found to have entered residential care, generally at an advanced age [42]. Entry to residential care or hospital and death were found to have increased rapidly with age.

The MELSHA survey was designed as a longitudinal survey to follow up the changing health, health service use and well-being among older Australians over 16 years ( 9 waves in total from 1994 to 2010) when their age increased (See Table 1). The participants in the baseline year 1994 were representative of older people aged 65 years and over who spoke English and lived in private dwellings in Metropolitan Melbourne. However, after the baseline year (1994), due to death, moving to residential care or other health issues, there was increasing sample attrition. However, no weight was used to adjust the influence of sample attrition on data representativeness.

After careful consideration of sample attrition and representativeness, the analyses in the current study only used data from 1994 to 2004 (the first 6 waves (10 years) with a sample size from 1000 in 1994 to 326 in 2004. Since the sample size was already very low in $2006(n=104)$, the inclusion of the last 3 waves would decrease the precision of our estimations.

The La Trobe University and Monash University Human Ethics Committees approved the study, and signed informed consent was obtained from all participants and participant anonymity was preserved. This ethics approval conforms to the provisions of the Declaration of Helsinki (as revised in Seoul 2008). 
Table 1. Participants across waves 1994-2010.

\begin{tabular}{cccccccccc}
\hline Sample Size & $\mathbf{1 9 9 4}$ & $\mathbf{1 9 9 6}$ & $\mathbf{1 9 9 8}$ & $\mathbf{2 0 0 0}$ & $\mathbf{2 0 0 2}$ & $\mathbf{2 0 0 4}$ & $\mathbf{2 0 0 6}$ & $\mathbf{2 0 0 8}$ & $\mathbf{2 0 1 0}$ \\
\hline Total in survey & 1000 & 789 & 646 & 589 & 438 & 326 & 104 & 201 & 132 \\
\hline (1) In 1994 residence & 1000 & 759 & 613 & 507 & NA & 300 & NA & 181 & 127 \\
\hline (2) Not in 1994 residence & & 22 & 27 & 21 & NA & 17 & NA & 17 & 5 \\
\hline (3) Unknown residence & 8 & 6 & 8 & NA & 9 & NA & 3 & 0 \\
\hline (4) No reply for this question & & & 53 & & & & & 34 & 34 \\
\hline In residential care and still alive & 18 & 31 & 39 & 39 & 34 & 35 & 34 \\
\hline In residential care and died & 33 & 51 & 61 & 81 & 107 & 116 & 117 & 117 \\
\hline Not in residential care and died & & 55 & 101 & 146 & 217 & 271 & 310 & 331 & 331 \\
\hline Alive but not in survey & & 105 & 171 & 165 & 225 & 262 & 435 & 317 & 386 \\
\hline Total & 1000 & 1000 & 1000 & 1000 & 1000 & 1000 & 1000 & 1000 \\
\hline
\end{tabular}

Data source: Melbourne Longitudinal Studies on Healthy Ageing (MELSHA) survey data 1994 to 2010. Only data from 1994 to 2004 was used in the current study.

\subsection{Measures}

Demographic data collected included age, gender, marital status, living conditions (living alone, housing tenure type) and main income source. Although the focus of this paper is on older women, the results of the older men in this sample have been presented, for comparative purposes.

\subsubsection{Measuring Sensory Loss (SL) and Unmet Needs}

In the current literature, vision loss and hearing loss have been defined either by passing specific thresholds in medical examinations/testing, for example, Kuang et al. [43] or subjectively using self-reported poor/fair vision and/or hearing capacities, for example, Yu et al. [44]. By following the definition of sensory loss used in previous studies [11,29], in this study, we only used questions relating to self-reported poor/fair vision and hearing to define sensory loss. The two questions relating to self-reported vision capacity included: (1) Do you currently use glasses or contact lenses? and (2) (With your glasses) is your eyesight (excellent/good/fair/poor/functionally or legally blind/totally blind)? The two questions relating to self-reported hearing capacity included: (1) Do you currently use a hearing aid? and (2) Is your hearing (with your hearing aid) (excellent/good/fair/poor)? Poor vision (or vision loss) was defined as self- reported poor/fair eyesight (with glasses). The unmet need for glasses was defined as having poor/fair vision while not currently using glasses or contact lenses. Poor hearing (or hearing loss) was defined as self- reported poor/fair hearing (using a hearing aid). The unmet need for hearing aids was defined as having poor/fair hearing while not using a hearing device. Dual sensory loss (DSL) was defined as self-reported vision loss plus hearing loss.

The longitudinal nature of MELSHA data also allows for the examination of the changes of hearing, vision and DSL over 2 years, 6 years and 10 years from 1994 to 2004. Data after 2004 were not included in this study, since the sample size was extremely small mainly due to mortality (See Table 1).

\subsubsection{Other Measures}

Self-rated general health was measured according to respondent's answers when they were asked to rate their own health compared to people of the same age. This variable was regrouped into two categories based on data distribution: (1) excellent/very good/good; (2) fair/poor. Mental health (as measured by the presence or absence of depression) was measured using a cut-off score of 5 or more on the Psychogeriatric Assessment Scales (PAS) [45] (score ranges were 0-12). Perceived current social activity level was used, where $1=$ not enough and $0=$ about right or too much to identify social health, as it represents both need and practice. Use of community services was categorised as 'yes' if a respondent answered 'yes' to either of the two questions: "Do you use any organized community 
services such as the home and community care program?"; "Who helps you with household duties or personal care which you cannot do on your own? Organized community services (e.g., home and community care program)?".

"Ageing in place" in this study is defined as a longitudinal outcome during the ten years study period (from 1994 to 2004) and was used instead of a current outcome for any of the survey years. "Ageing in place" refers to women (or men) who had remained in their 1994 residence until the survey year of 2004, or within two years before their death. Those women (or men) who had moved or entered residential care either before the last wave of the survey or two years before their death were classified as "not aged in place" [42]. Some people in the sample could not be defined due to attrition (being "alive but not in the survey") after 1994. During the 10 years from 1994 to 2004, 176 women were defined as "aged in place", 120 women were defined as "not aged in place" and 237 women could not be defined. From 1994 to 2004, there were 249 men defined as "aged in place", 76 men defined as "not aged in place" and 142 men could not be defined due to attrition.

\subsection{Statistical Analyses}

The longitudinal nature of MELSHA data has been used to: (1) investigate the prevalence and persistence of DSL over time in the baseline year, and after 2, 6 and 10 years based on data in 1994, 1996, 2000 and 2004 and (2) to estimate the baseline predictors of ageing in place which were defined based on the 10 years survey data from 1994 to 2004. Unlike other health conditions which were more likely to be chronic and had long term impact, and although the prevalence of dual sensory loss (DSL) increased as a result of ageing, DSL could be improved greatly by using glasses and/or hearing aids. Consequently, this study aimed to investigate the health inequalities in terms of the prevalence of DSL, unmet needs for glasses/hearing aids and their current impacts on service use and well-being. Long-term impacts of DSL on health service use and well-being were not felt to be meaningful, as there were very few instances of persistent DSL over time. Consequently, it was decided to use the baseline full sample data to investigate the current impact of DSL on service use and well-being, as well as the baseline predictors of ageing in place during 10 years, while conducting the robustness check of regression results using 1994 data including both women and men in one model, as well as using 2004 data for women and men separately in two models.

Although the pooled data of all waves had been initially investigated, there were several reasons as to why the pooled data of all waves was not reported in our final analysis-reasons include concern about autocorrelation and dependence of the residuals generated by using the pooled data from longitudinal survey with repeated individuals and secondly, concern regarding the lack of weights to adjust for the impact of sample attrition. In addition, unmet need for glasses and hearing aids cannot be defined consistently in years 1998 and 2002. The confidence level of $90 \%$ (or an Alpha level of 10\% relates to a Type 1 error) was used to test the significance of our estimates in this study due to the relatively small sample size of the MELSHA survey.

\section{Results}

\subsection{Descriptive Analysis}

Overall, at baseline, there were 1000 people in the total sample, with 533 women and 467 men. See Table 2. 
Table 2. Individual characteristics, prevalence of dual sensory loss (DSL) and unmet needs by gender in 1994 and 2004.

\begin{tabular}{|c|c|c|c|c|c|c|c|c|c|}
\hline \multirow{2}{*}{\multicolumn{2}{|c|}{ Individual Characteristics }} & \multicolumn{4}{|c|}{ Year 1994} & \multicolumn{4}{|c|}{ Year 2004} \\
\hline & & \multicolumn{2}{|c|}{ Women } & \multicolumn{2}{|c|}{ Men } & \multicolumn{2}{|c|}{ Women } & \multicolumn{2}{|c|}{ Men } \\
\hline Variables & Values & $n$ & $\%$ & $n$ & $\%$ & $n$ & $\%$ & $n$ & $\%$ \\
\hline All & All & 533 & 100 & 467 & 100 & 166 & 100 & 148 & 100 \\
\hline \multirow{2}{*}{ Age group } & $65-74$ & 326 & 61.2 & 316 & 67.7 & & & & \\
\hline & $75+$ & 207 & 38.8 & 151 & 32.3 & 166 & 100 & 148 & 100 \\
\hline \multirow{3}{*}{ Marital status } & Currently living with partner & 206 & 38.7 & 372 & 79.7 & 53 & 32.3 & 110 & 76.4 \\
\hline & Previously with a partner & 301 & 56.5 & 75 & 16.1 & 105 & 64.0 & 28 & 19.4 \\
\hline & Never married & 26 & 4.9 & 20 & 4.3 & 6 & 3.7 & 6 & 4.2 \\
\hline \multirow{2}{*}{ Living alone } & No & 269 & 50.5 & 396 & 84.8 & 68 & 41.5 & 114 & 78.1 \\
\hline & Yes & 264 & 49.5 & 71 & 15.2 & 96 & 58.5 & 32 & 21.9 \\
\hline \multirow{5}{*}{ Tenure } & Own house & 441 & 83.7 & 412 & 88.2 & 146 & 89.0 & 134 & 91.8 \\
\hline & Paying off house & 16 & 3.0 & 21 & 4.5 & 1 & 0.6 & 2 & 1.4 \\
\hline & Public renter & 25 & 4.7 & 9 & 1.9 & 5 & 3.1 & 1 & 0.7 \\
\hline & Private renter & 19 & 3.6 & 15 & 3.2 & 4 & 2.4 & 1 & 0.7 \\
\hline & Other & 26 & 4.9 & 10 & 2.1 & 8 & 4.9 & 8 & 5.5 \\
\hline \multirow{2}{*}{ Income sources } & Government benefits & 368 & 70.6 & 293 & 63.7 & 110 & 69.6 & 79 & 57.7 \\
\hline & Private income & 153 & 29.4 & 167 & 36.3 & 48 & 30.4 & 58 & 42.3 \\
\hline \multirow{4}{*}{$\begin{array}{l}\text { Dual Sensory Loss } \\
\text { (DSL) }\end{array}$} & Good vision and hearing & 295 & 55.9 & 257 & 55.3 & 82 & 49.7 & 69 & 46.9 \\
\hline & Poor vision only & 94 & 17.8 & 51 & 11.0 & 18 & 10.9 & 13 & 8.8 \\
\hline & Poor hearing only & 80 & 15.2 & 106 & 22.8 & 34 & 20.6 & 46 & 31.3 \\
\hline & Dual sensory loss & 59 & 11.2 & 51 & 11.0 & 31 & 18.8 & 19 & 12.9 \\
\hline \multirow{2}{*}{$\begin{array}{l}\text { Unmet needs for } \\
\text { hearing aids }\end{array}$} & No unmet needs & 418 & 79.2 & 349 & 75.1 & 131 & 79.4 & 114 & 77.6 \\
\hline & With unmet needs & 110 & 20.8 & 116 & 25.0 & 34 & 20.6 & 33 & 22.5 \\
\hline
\end{tabular}

Data source: MELSHA 1994-2004. Note: The numbers in the cells with a sample size smaller than 20 should be interpreted with caution. Due to some small but different missing information for each of the variables, the sum of the numbers at the top by age group, is slightly different from the addition of some of the other variables. Table S1 presents the prevalence rate of DSL among older Australians aged 65 and over for women compared to men in all waves from 1994 to 2004 by age group.

At baseline (in 1994), there were 326 women aged 65-74 years and 207 women aged 75 years and over, compared to 316 men aged 65-74 years and 151 men aged 75 years and over. Amongst the 533 women, $38.7 \%$ were currently living with a partner, whilst $56.5 \%$ were widowed, divorced or separated, and $4.9 \%$ never married. In 2004, the sample size decreased for both men and women to 166 women and 148 men, all aged 75 years and over. Consistent with the trends in 1994, in 2004, 32.3\% of women were living with a partner, whilst $64.0 \%$ were widowed, divorced or separated and $3.7 \%$ never married. As is evident from Table 2, women were more likely to have no partner, live alone, be dependent on government income or be public renters compared to men in both 1994 and 2004.

Examining vision loss, hearing loss, and DSL and good vision and hearing separately, a proportion of women consistently reported poor vision in $1994(n=94 ; 17.8 \%)$ and in $2004(n=18 ; 10.9 \%)$. In 1994, 80 women $(15.2 \%)$ reported poor hearing, and this proportion increased to $20.6 \%(n=34)$ in 2004 when age increased. The number of men reporting poor vision $(n=51 ; 11.0 \%)$ or poor hearing $(n=106$; $22.8 \%)$ in 1994 proportionately decreased in 2004 for poor vision $(n=13 ; 8.8 \%)$ and increased for poor hearing $(n=46 ; 31.3 \%)$. In both 1994 and 2004, women had a higher proportion of poor vision, while men had a higher proportion of poor hearing. The proportion of DSL increased from 1994 to 2004 ( $11.2 \%$ to $18.8 \%$ for women and from $11.0 \%$ to $12.9 \%$ for men) when age increased. The rate of unmet needs for hearing aids in 1994 was higher for men than women in both years of 1994 and $2004(25.0 \%$ for men compared to $20.8 \%$ for women in $1994 ; 22.5 \%$ for men compared to $20.6 \%$ for women in 2004). Unmet needs for glasses were low (less than $1 \%$ ) and hence not reported further. It was also evident 
that the proportion of older women with good vision and hearing decreased from $55.9 \%(n=295)$ in 1994 (total sample of women $=533$ ) to $49.7 \%(n=82)$ in 2004 (total sample $n=166$ ).

Table 3 presents the sensory capacity and the use of glasses and hearing aids in years 1994, 2000 and 2004. From Table 3, it is evident that the prevalence rate of DSL in the cohort increased over the ten years study period, with little and no significant differences between the genders. Women were more likely to report poor vision, while men were more likely to have poor hearing. Though the proportion of poor hearing was only slightly lower than that of poor vision, the majority (more than $90 \%$ ) of older Australian women and men had glasses since earlier old ages, while fewer older women and men (11-37\%) used hearing aids. The proportion of wearing glasses and poor vision were relatively constant over time when aged increased, while the proportion of poor hearing and using hearing aids increased by age. The unmet need for glasses was lower than $2 \%$, while the unmet need for hearing aids was around $20-25 \%$.

Table 3. Sensory capacity and the use of glasses and hearing aids in 1994, 2000 and 2004.

\begin{tabular}{ccccccc}
\hline Sensory Capacity and Device Use & \multicolumn{3}{c}{ Women } & \multicolumn{3}{c}{ Men } \\
\cline { 2 - 7 } & $\mathbf{1 9 9 4}$ & $\mathbf{2 0 0 0}$ & $\mathbf{2 0 0 4}$ & $\mathbf{1 9 9 4}$ & $\mathbf{2 0 0 0}$ & $\mathbf{2 0 0 4}$ \\
\hline 1.1 Wearing glasses & $96.3 \%$ & $93.4 \%$ & $95.2 \%$ & $96.2 \%$ & $93.2 \%$ & $95.2 \%$ \\
1.2 Poor vision (with glasses if there are) & $28.9 \%$ & $26.0 \%$ & $29.5 \%$ & $22.3 \%$ & $23.6 \%$ & $21.8 \%$ \\
1.3 Unmet needs for glasses & $1.0 \%$ & $2.4 \%$ & $1.8 \%$ & $1.1 \%$ & $1.2 \%$ & $0.7 \%$ \\
\hline 2.1 Using hearing aids & $11.6 \%$ & $15.6 \%$ & $28.5 \%$ & $18.0 \%$ & $31.2 \%$ & $37.0 \%$ \\
2.2 Poor hearing (with aids if there are) & $26.3 \%$ & $32.3 \%$ & $39.4 \%$ & $33.8 \%$ & $46.0 \%$ & $44.2 \%$ \\
2.3 Unmet need for hearing aids & $20.8 \%$ & $23.3 \%$ & $20.6 \%$ & $25.0 \%$ & $24.0 \%$ & $22.5 \%$ \\
\hline 3. DSL & $11.2 \%$ & $14.9 \%$ & $18.8 \%$ & $11.0 \%$ & $16.8 \%$ & $12.9 \%$ \\
\hline
\end{tabular}

Data source: MELSHA 1994-2004.

Unlike other chronic diseases, DSL might be improved by using glasses and/or hearing aids. Therefore, whether the sensory loss was for a short term or was persistent for a longer time was examined by investigating the transitions to DSL as it occurred in 2 years, 6 years, and 10 years post-baseline (See Table 4).

Table 4. Persistent DSL, vision loss and hearing loss in 2 years, 6 years and 10 years post baseline.

\begin{tabular}{ccccc}
\hline \multirow{2}{*}{ Persistence of DSL } & \multicolumn{2}{c}{ Women } & \multicolumn{2}{c}{ Men } \\
\cline { 2 - 5 } & $\boldsymbol{n}$ & $\%$ & $n$ & $\%$ \\
\hline DSL in both 1994 and 1996 & 23 & $5.4 \%$ & 18 & $4.9 \%$ \\
\cline { 2 - 5 } DSL in both 1994 and 2000 & 9 & $3.2 \%$ & 10 & $4.0 \%$ \\
\cline { 2 - 5 } DSL in both 1994 and 2004 & 5 & $3.1 \%$ & 5 & $3.4 \%$ \\
\hline Poor hearing in both 1994 and 1996 & 78 & $18.3 \%$ & 100 & $27.4 \%$ \\
\cline { 2 - 5 } Poor hearing in both 1994 and 2000 & 45 & $15.8 \%$ & 63 & $25.2 \%$ \\
\cline { 2 - 5 } Poor hearing in both 1994 and 2004 & 24 & $14.7 \%$ & 31 & $21.1 \%$ \\
\hline Poor vision in both 1994 and 1996 & 62 & $14.6 \%$ & 40 & $11.0 \%$ \\
\cline { 2 - 5 } Poor vision in both 1994 and 2000 & 35 & $12.2 \%$ & 26 & $10.4 \%$ \\
\cline { 2 - 5 } Poor vision in both 1994 and 2004 & 16 & $9.7 \%$ & 13 & $8.8 \%$ \\
\hline
\end{tabular}

Data source: MELSHA 1994-2004. Note: The numbers in the cells with a sample size smaller than 20 should be interpreted with caution. For more details, see Table S2.

As is apparent from Table 4, persistent DSL for women was higher in the 2 years post baseline, whilst it was very similar at about 5 and 10 years post baseline (5.4\% in 2 years, compared to $3.2 \%$ in 6 years and $3.1 \%$ in 10 years). In comparison, for men, persistent DSL decreased from a short-term to a long-term condition ( $4.9 \%$ at 2 years post-baseline compared to $4.0 \%$ at 6 years and $3.4 \%$ at 10 years 
post-baseline). Women had a relatively higher proportion of persistent vision loss $(14.6 \%, 12.2 \%$ and $9.7 \%$ for women compared to $11.0 \%, 10.4 \%$ and $8.8 \%$ for men in 2 years, 6 years and 10 years post-baseline respectively), while men had a relatively higher proportion of persistent hearing loss (27.4\%, $25.2 \%$ and $21.1 \%$ for men when compared to $18.3 \%, 15.8 \%$ and $14.7 \%$ for women in 2 years, 6 years and 10 years post-baseline respectively). For both men and women, the proportion of persistent hearing loss was higher than that of persistent vision loss at any of the three time points.

In regards to the demographic factors associated with DSL, it was apparent that in 1994 (see the first part of Table 5), the prevalence of DSL for women was significantly higher amongst those aged 75 years and over, previously with a partner (widowed, separated or divorced), living alone or those with public income as their main source of income. In 1994, the prevalence of DSL was similar among women and men $(11.2 \%$ compared to $11.0 \%)$, while it became much higher in women than for men after 10 years, in 2004 (18.8\% when compared to 12.9\%). For men, the prevalence of DSL in 1994 was significantly higher amongst those previously living with a partner, living alone, or for those with public income as their main source of income.

In comparison, in 2004 (see the second part of Table 5), the prevalence of DSL increased for women after 10 years (from $11.2 \%$ to $18.8 \%$ ) and was still significantly higher amongst those women without a partner (widowed, separated or divorced), living alone or with public income as their main source of income. The prevalence of DSL for men had increased from $11.0 \%$ in 1994 to $12.9 \%$ in 2004 and was still higher amongst those men without a partner (widowed, separated or divorced) (16.2\% in 1994 and $17.9 \%$ in 2004), but became lower for those living alone (15.7\% in 1994 and $12.5 \%$ in 2004). The gap in the proportion of those with DSL by major income source from government benefits were larger in both years (1994 and 2004) for women (14.2\% compared to $4.0 \%$ in 1994 and $22.0 \%$ compared to $12.5 \%$ in 2004), whilst this gap decreased for men (12.7\% compared to $7.8 \%$ in 1994 and $13.9 \%$ compared to $10.3 \%$ in 2004).

Table 5. DSL by individual characteristics for women and men in 1994 and 2004.

\begin{tabular}{|c|c|c|c|c|c|c|c|c|c|}
\hline \multirow{2}{*}{\multicolumn{2}{|c|}{ Individual Characteristics }} & \multicolumn{4}{|c|}{ With DSL 1994} & \multicolumn{4}{|c|}{ With DSL 2004} \\
\hline & & \multicolumn{2}{|c|}{ Women } & \multicolumn{2}{|c|}{ Men } & \multicolumn{2}{|c|}{ Women } & \multicolumn{2}{|c|}{ Men } \\
\hline Variables & Values & $n$ & $\%$ & $n$ & $\%$ & $n$ & $\%$ & $n$ & $\%$ \\
\hline All & All & 59 & 11.2 & 51 & 11.0 & 31 & 18.8 & 19 & 12.9 \\
\hline \multirow{2}{*}{ Age group } & $65-74$ & 32 & 9.9 & 36 & 11.4 & & & & \\
\hline & $75+$ & 27 & 13.3 & 15 & 10.1 & 31 & 18.8 & 19 & 12.9 \\
\hline \multirow{3}{*}{ Marital status } & Currently living with partner & 14 & 6.8 & 37 & 10.0 & 6 & 11.3 & 12 & 11.0 \\
\hline & Previously with a partner & 44 & 14.8 & 12 & 16.2 & 24 & 23.1 & 5 & 17.9 \\
\hline & Never married & 1 & 4.0 & 2 & 10.0 & 1 & 16.2 & 1 & 16.7 \\
\hline \multirow{2}{*}{ Living alone } & No & 18 & 6.7 & 40 & 10.1 & 8 & 11.9 & 15 & 13.3 \\
\hline & Yes & 41 & 15.7 & 11 & 15.7 & 22 & 22.9 & 4 & 12.5 \\
\hline \multirow{5}{*}{ Tenure } & Own house & 47 & 10.7 & 45 & 11.0 & 25 & 17.2 & 16 & 12.0 \\
\hline & Paying off house & 1 & 6.3 & 5 & 23.8 & 0 & 0.0 & 0 & 0.0 \\
\hline & Public renter & 3 & 12.0 & 0 & 0.0 & 0 & 0.0 & 0 & 0.0 \\
\hline & Private renter & 2 & 10.5 & 0 & 0.0 & 1 & 25.0 & 0 & 0.0 \\
\hline & Other & 6 & 23.1 & 1 & 10.0 & 4 & 50.0 & 2 & 25.0 \\
\hline \multirow{2}{*}{$\begin{array}{l}\text { Main income } \\
\text { resource }\end{array}$} & Government benefits & 52 & 14.2 & 37 & 12.7 & 24 & 22.0 & 11 & 13.9 \\
\hline & Private income & 6 & 4.0 & 13 & 7.8 & 6 & 12.5 & 6 & 10.3 \\
\hline
\end{tabular}

Data source: MELSHA 1994-2004. Note: The numbers in the cells with a sample size smaller than 20 should be interpreted with caution. Due to some small but different missing information for each of the variables, the sum of the numbers at the top by age group, is slightly different from the addition of some of the other variables.

The number of medical conditions for women and men with or without DSL is shown in Table 6. It is apparent from Table 6 that in 1994, older women with DSL or poor vision had the highest number of medical conditions (5.1 and 5.2 respectively) compared to women with good sensory acuity or "hearing loss only". In 2004 with advancing age, older women with DSL or poor hearing had the 
highest number of medical conditions (4.6 and 5.2 respectively) compared to those with good sensory acuity or "poor vision only". In contrast, the variation in the number of medical conditions related to poor vision or hearing were much smaller for men compared to women.

Table 6. Comorbidity of DSL with other medical conditions in 1994 and 2004.

\begin{tabular}{ccccc}
\hline $\begin{array}{c}\text { Comorbidity of DSL } \\
\text { with Medical Conditions }\end{array}$ & \multicolumn{2}{c}{ Women } & \multicolumn{2}{c}{ Men } \\
\hline Sensory Status & $\begin{array}{c}\text { Number of } \\
\text { Medical } \\
\text { Conditions 1994 } \\
\text { (Mean) }\end{array}$ & $\begin{array}{c}\text { Number of } \\
\text { Medical } \\
\text { Conditions 2004 } \\
\text { (Mean) }\end{array}$ & $\begin{array}{c}\text { Number of } \\
\text { Medical } \\
\text { Conditions 1994 } \\
\text { (Mean) }\end{array}$ & $\begin{array}{c}\text { Number of } \\
\text { Medical } \\
\text { Conditions 2004 } \\
\text { (Mean) }\end{array}$ \\
\hline Good vision and hearing & $2.6(296)$ & $3.0(82)$ & $3.0(257)$ & $3.9(69)$ \\
Poor vision only & $5.2(94)$ & $3.1(18)$ & $3.2(51)$ & $3.6(13)$ \\
Poor hearing only & $3.0(80)$ & $5.2(34)$ & $4.0(106)$ & $3.4(46)$ \\
Dual sensory loss & $5.1(59)$ & $4.6(31)$ & $3.3(51)$ & $2.9(19)$ \\
\hline
\end{tabular}

Data source: MELSHA survey data; no weights were used. Notes: Wave 1 (in 1994): 25 conditions asked. Wave 6 (in 2004): 17 conditions asked. The numbers in brackets are the sample size. The estimations based on a sample size smaller than 20 should be interpreted with caution.

Due to the small sample size remaining in 2004, we used the 1994 data to examine the univariate and multivariate associations between DSL and health and social outcomes. Table 7 reports the cross-tabulations of women and men with a range of sensory acuities and the self-reported outcomes including living conditions, health, depression, social activities, community services and ageing in place. From the top part of Table 7, it is apparent that amongst older women with DSL: (1) 69.5\% were living alone (which is a much higher percentage than women with no sensory loss $(46.8 \%)$ or one sensory loss only (46-48\%); (2) 34.5\% reported poor/fair general health, followed by $29.8 \%$ for those with vision loss, compared to women with no sensory loss $(13.3 \%)$ or those with hearing loss (10.1\%); (3) $35.6 \%$ were depressed, followed by $26.7 \%$ of women with vision loss, $22.5 \%$ of women with hearing loss, compared to those with no sensory loss (12.9\%); (4) $24.1 \%$ perceived inadequate social activity, compared to those with hearing loss (29.9\%), with vision loss $(19.4 \%)$ or no sensory loss (16.3\%); (5) $23.7 \%$ used community services, compared to those with hearing loss (25.0\%), vision loss $(18.2 \%)$ and those with no sensory loss (10.8\%) and (6) $47.2 \%$ did not have ageing in place, closely followed by those with no sensory loss $(41.3 \%)$, and those with hearing loss $(40.0 \%)$ compared to those with vision loss (33.3\%).

There was less variation in DSL prevalence by individual characteristics in men compared to women (see the bottom part of Table 7). For older men with DSL, the following is apparent: (1) they were the most likely to report poor/fair health $(29.4 \%)$, perceive inadequate social activities $(26.0 \%)$, use community services $(15.2 \%)$ and live alone $(21.6 \%)$; (2) older men with poor hearing, were the most likely to report being depressed (16.0\%) and (3) older men with poor vision, were the most likely not to have ageing in place (31.6\%). 
Table 7. DSL and associated social and health outcomes in 1994.

\begin{tabular}{|c|c|c|c|c|c|c|c|c|c|c|c|c|c|}
\hline \multirow{2}{*}{$\begin{array}{c}\text { Women } \\
\text { DSL } 1994\end{array}$} & \multirow{2}{*}{$\begin{array}{c}\text { ALL } \\
n\end{array}$} & \multicolumn{2}{|c|}{$\begin{array}{c}\text { Living } \\
\text { Alone (1994) }\end{array}$} & \multicolumn{2}{|c|}{$\begin{array}{c}\text { Self-Reported } \\
\text { Poor/Fair } \\
\text { Health } 1994\end{array}$} & \multicolumn{2}{|c|}{$\begin{array}{c}\text { Depressed } \\
1994\end{array}$} & \multicolumn{2}{|c|}{$\begin{array}{c}\text { Inadequate } \\
\text { Social } \\
\text { Activities } \\
1994\end{array}$} & \multicolumn{2}{|c|}{$\begin{array}{c}\text { Community } \\
\text { Service Use } \\
1994\end{array}$} & \multicolumn{2}{|c|}{$\begin{array}{l}\text { Not Aged in } \\
\text { Place } \\
\text { 1994-2004 }\end{array}$} \\
\hline & & $n$ & $\%$ & $n$ & $\%$ & $n$ & $\%$ & $n$ & $\%$ & $n$ & $\%$ & & $\%$ \\
\hline $\begin{array}{l}\text { Good vision } \\
\text { and hearing } \\
\text { (no-SL) }\end{array}$ & 295 & 138 & 46.8 & 39 & 13.3 & 38 & 12.9 & 48 & 16.3 & 30 & 10.8 & 64 & 41.3 \\
\hline $\begin{array}{l}\text { Poor vision } \\
\text { only (VL) }\end{array}$ & 94 & 44 & 46.8 & 28 & 29.8 & 25 & 26.7 & 18 & 19.4 & 16 & 18.2 & 19 & 33.3 \\
\hline $\begin{array}{c}\text { Poor } \\
\text { hearing } \\
\text { only (HL) }\end{array}$ & 80 & 38 & 47.5 & 8 & 10.1 & 18 & 22.5 & 23 & 29.9 & 18 & 25.0 & 18 & 40.0 \\
\hline All women & 528 & 261 & 49.4 & 95 & 18.1 & 102 & 19.3 & 103 & 19.7 & 78 & 15.7 & 118 & 40.3 \\
\hline Men & ALL & & & $\begin{array}{r}\text { Self- } \\
\text { Po } \\
\text { Hea }\end{array}$ & $\begin{array}{l}\text { ported } \\
\text { Fair } \\
1994\end{array}$ & Dep & $\begin{array}{l}\text { ssed } \\
4\end{array}$ & $\begin{array}{r}\text { Inad } \\
\text { Sc } \\
\text { Act } \\
1\end{array}$ & $\begin{array}{l}\text { uate } \\
\text { al } \\
\text { ties } \\
4\end{array}$ & $\begin{array}{r}\text { Com } \\
\text { Serv } \\
1\end{array}$ & $\begin{array}{l}\text { unity } \\
\text { Use }\end{array}$ & $\begin{array}{r}\text { Not } \\
\text { in } \\
199\end{array}$ & $\begin{array}{l}\text { eing } \\
\text { ice } \\
004\end{array}$ \\
\hline DSL 1994 & $n$ & $n$ & $\%$ & $n$ & $\%$ & $n$ & $\%$ & $n$ & $\%$ & $n$ & $\%$ & $n$ & $\%$ \\
\hline $\begin{array}{l}\text { Good vision } \\
\text { and hearing }\end{array}$ & 257 & 40 & 15.6 & 36 & 14.2 & 19 & 7.4 & 31 & 12.1 & 13 & 5.4 & 36 & 21.2 \\
\hline All men & 465 & 70 & 15.1 & 82 & 17.8 & 49 & 10.5 & 77 & 16.6 & 26 & 6.1 & 76 & 23.4 \\
\hline
\end{tabular}

Data source: MELSHA 1994-2004. Note: The numbers in the cells with a sample size smaller than 20 should be interpreted with caution.

\subsection{Regression Results}

Multivariate regression analysis based on 1994 outcomes or predictors is shown in Table 8 and full regression results in Table S3 for women and Table 9 and Table S4 for men. As is apparent from Table 8, after controlling for other variables, for women: (1) having DSL had a significant impact on self-reported general health, depression, inadequate social activities and community service use; (2) "poor vision only" had a significant impact on self-reported general health and depression; (3) "poor hearing only" had a significant impact on depression, inadequate social activities and community service use.

There are also some common and some different influence of the type of sensory loss experienced by women including: (1) DSL, poor vision only or poor hearing only all had no significant influence on ageing in place but all had a significant influence on depression; (2) poor vision had a significant influence on self-reported health, while poor hearing had a significant influence on community service use and DSL on both; and (3) poor hearing and DSL, but not poor vision, had a significant influence on perceived inadequate social activities indicating that social participation and independence can be improved for those with poor hearing and DSL.

Further findings from the full regression model (Table S3) show that: (1) those with private income sources were less likely to have DSL, while those living alone were more likely to have DSL; (2) The unmet need for hearing aids was associated with living alone but was not significantly related to other 
socioeconomic status (SES). This confirms that women living alone were the most disadvantaged in terms of having DSL and the unmet needs for hearing aids.

Table 8. Multivariate regression results on DSL prevalence and its associated outcomes in 1994 for women.

\begin{tabular}{|c|c|c|c|c|c|c|c|}
\hline $\begin{array}{l}\text { Dependent } \\
\text { Variables for } \\
\text { Women }\end{array}$ & DSL 1994 & $\begin{array}{l}\text { Unmet } \\
\text { Needs for } \\
\text { Hearing } \\
\text { Aids } 1994\end{array}$ & $\begin{array}{l}\text { Poor/Fair } \\
\text { Health }\end{array}$ & $\begin{array}{c}\text { Depressed } \\
1994\end{array}$ & $\begin{array}{c}\text { Perceived } \\
\text { Inadequate } \\
\text { Social } \\
\text { Activities } 1994\end{array}$ & $\begin{array}{l}\text { Community } \\
\text { Service } \\
\text { Use } 1994\end{array}$ & $\begin{array}{l}\text { Aged in } \\
\text { Place } \\
\text { 1994-2004 }\end{array}$ \\
\hline $\begin{array}{c}\text { Sensory capacity } \\
1994\end{array}$ & \multicolumn{7}{|c|}{ Estimated coefficient } \\
\hline \multicolumn{8}{|l|}{$\begin{array}{c}\text { Good vision and } \\
\text { hearing } \\
\text { (Ref. group) }\end{array}$} \\
\hline Poor vision only & & & $1.035 *$ & $0.762 *$ & 0.257 & 0.353 & 0.590 \\
\hline $\begin{array}{l}\text { Poor hearing } \\
\text { only }\end{array}$ & & & -0.229 & $0.580 *$ & $0.799 *$ & $0.957 *$ & 0.132 \\
\hline R-square & 0.079 & 0.012 & 0.079 & 0.0547 & 0.022 & 0.1087 & 0.062 \\
\hline Sample & 517 & 517 & 514 & 517 & 493 & 488 & 287 \\
\hline
\end{tabular}

Data source: MELSHA survey data; no weights were used. Note: * indicates significance at the $10 \%$ level. Major demographics and socioeconomic status (including age group, gender, marital status, living alone, housing tenure type, main income source) are controlled for in all these regression models. The estimated coefficients from the full models are reported in Table S3. Ref. group = reference group.

Table 9. Multivariate regression results on DSL prevalence and its associated outcomes, 1994 men.

\begin{tabular}{|c|c|c|c|c|c|c|c|}
\hline $\begin{array}{l}\text { Dependent } \\
\text { Variables for } \\
\text { Men }\end{array}$ & $\begin{array}{l}\text { DSL } \\
1994\end{array}$ & $\begin{array}{c}\text { Unmet } \\
\text { Needs for } \\
\text { Hearing } \\
\text { Aids } 1994\end{array}$ & $\begin{array}{c}\text { Self-Reported } \\
\text { Poor/Fair } \\
\text { Health } 1994\end{array}$ & $\begin{array}{c}\text { Depressed } \\
1994\end{array}$ & $\begin{array}{c}\text { Perceived } \\
\text { Inadequate } \\
\text { Social } \\
\text { Activities } 1994\end{array}$ & $\begin{array}{c}\text { Community } \\
\text { Service } \\
\text { Use } 1994\end{array}$ & $\begin{array}{l}\text { Aged in } \\
\text { Place } \\
\text { 1994-2004 }\end{array}$ \\
\hline $\begin{array}{l}\text { Sensory capacity } \\
1994\end{array}$ & \multicolumn{7}{|c|}{ Estimated coefficient } \\
\hline \multicolumn{8}{|l|}{$\begin{array}{l}\text { Good vision and } \\
\text { hearing (Ref. } \\
\text { group) }\end{array}$} \\
\hline Poor vision only & & & 0.424 & 0.572 & $0.676^{*}$ & -1.328 & -0.580 \\
\hline $\begin{array}{c}\text { Poor hearing } \\
\text { only }\end{array}$ & & & 0.531 * & $0.855^{*}$ & $0.663 *$ & 0.021 & -0.289 \\
\hline $\begin{array}{c}\text { Dual sensory } \\
\text { loss }\end{array}$ & & & $0.832 *$ & 0.528 & $1.032 *$ & $1.265^{*}$ & -0.317 \\
\hline Constant & -2.021 & -1.188 & -1.687 & -2.828 & -2.277 & -3.194 & 2.006 \\
\hline R-square & 0.0293 & 0.0218 & 0.0616 & 0.0539 & 0.056 & 0.158 & 0.097 \\
\hline Sample & 435 & 458 & 453 & 450 & 457 & 394 & 318 \\
\hline
\end{tabular}

For comparative purposes, we have also reported the multiple regression results for men in Table 9 (and Table S4). The comparison of the estimated coefficients of sensory loss for women to men (Table 8 to Table 9) shows that there are some commonalities and differences in the findings for men and women and are as follows: (1) DSL had a significant influence on self-reported general health, community service use and inadequate social activities for both women and men, whilst DSL had a significant 
impact on depression for women only; (2) "Poor vision only" had a significant impact on self-reported general health and depression amongst women only, and on inadequate social activities amongst men only; (3) "Poor hearing only" had a significant impact on depression and inadequate social activities for both women and men, on community service use in women only, and on self-reported health in men only; and (4) there was no significant influence of DSL, poor vision or poor hearing on ageing in place for both women and men.

The further comparison of full regression results of women to men (Table S3 to Table S4) indicates that: (1) living alone was positively associated with both DSL and the unmet need for hearing aids among women; (2) being a private renter was positively associated with the unmet need for hearing aids among men; and (3) private income was negatively associated with DSL for both men and women.

\subsection{Robustness Check}

Women and men generally have different social and health outcomes. Table 10 (and Table S5) reports the multiple regression results for persons (including both women and men in one model) with gender controlled as a predictor. The significant influence of DSL, poor vision, poor hearing on social and health outcomes are found to be similar and robust as shown in Table 8.

Table 10. Multivariate regression results on DSL prevalence and its associated outcomes in 1994, all persons.

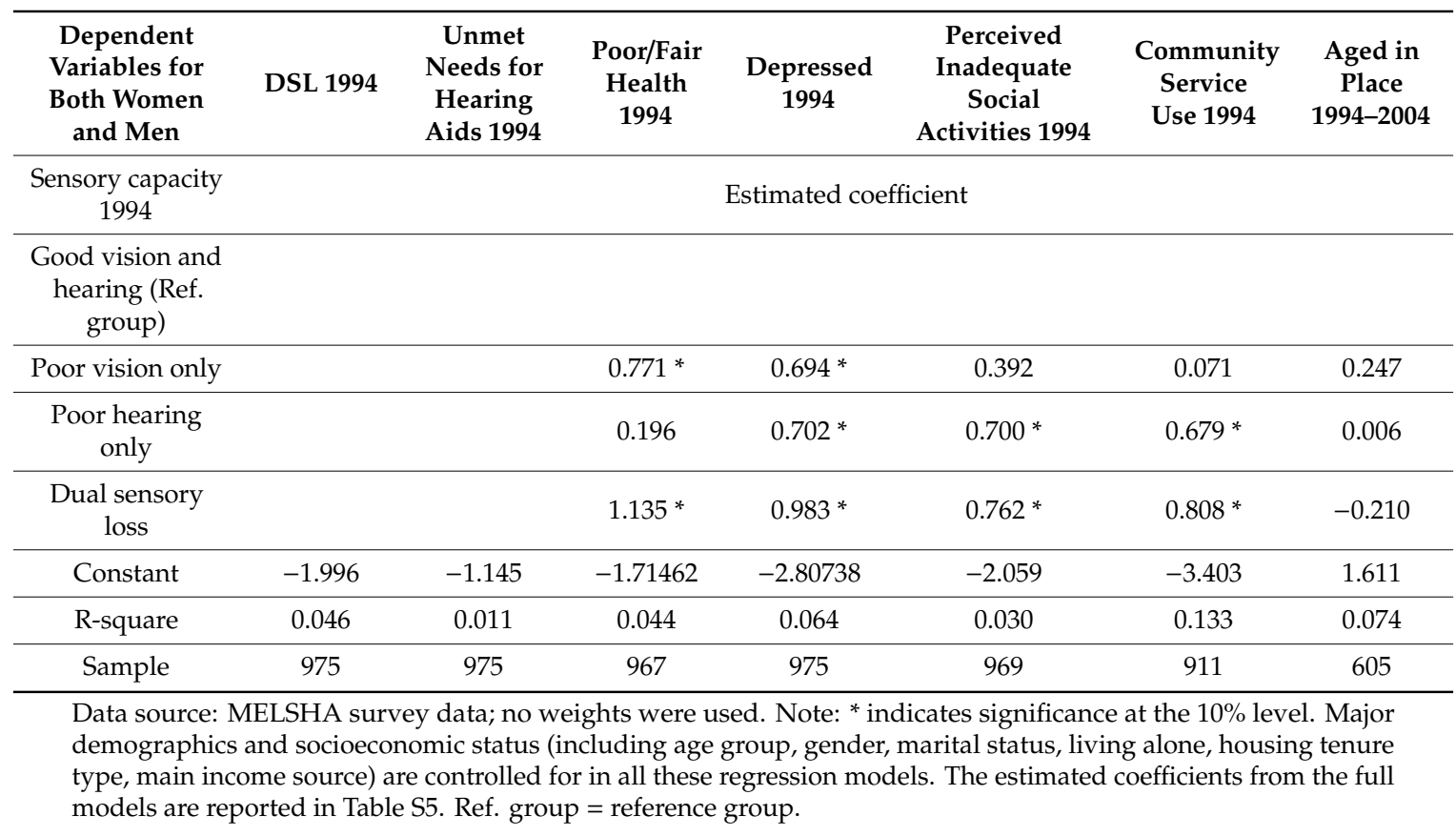

Since there was increasing sample attrition (attributed to death or other health issues) after the baseline year (1994), the robustness of the regression results (evident in Table 8 for women in 1994 and Table 9 for men in 1994) was checked using 2004 data and can be viewed in Table 11 for women in 2004 and Table 12 for men in 2004. As is evident from Table 11, the significant influence of DSL on self-reported general health, depression, perceived social activities and community service use; and the influence of poor hearing on perceived social activities and community service use amongst women found in 1994 are robust when using the 2004 data although the sample size in 2004 is much smaller than in 1994. 
Table 11. Multivariate regression results on DSL incidence and its influences, 2004 women.

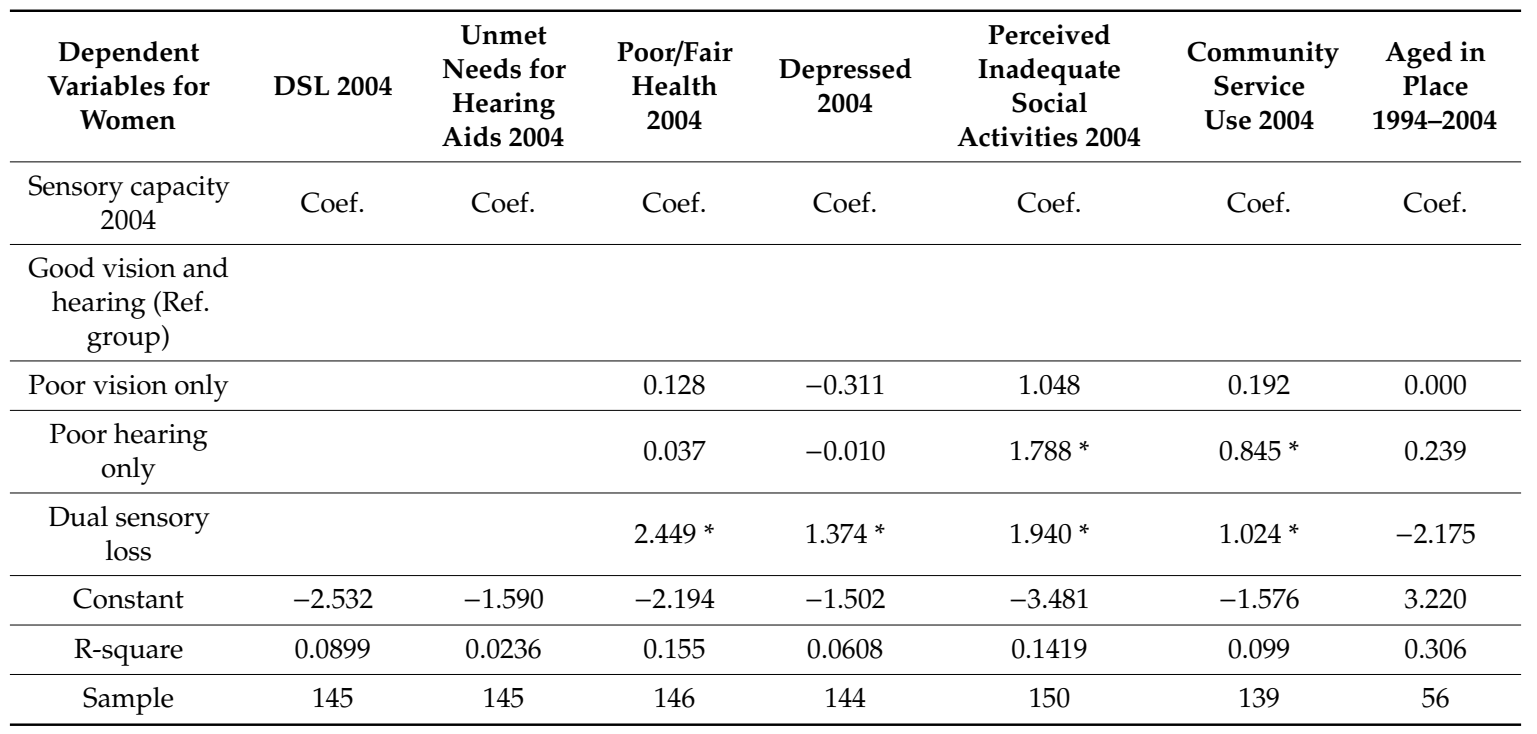

Data source: MELSHA survey data; no weights were used. Note: ${ }^{*}$ indicates significance at the $10 \%$ level. Major demographics and socioeconomic status (including age group, gender, marital status, living alone, housing tenure type, main income source) are controlled for in all these regression models. The estimated coefficients from the full models are reported in Table S6. Ref. group = reference group.

For men, the influence of poor vision on perceived inadequate social activities and the influence of DSL on poor/fair self-reported general health are still significant in 2004 as in 1994, while the significant influence of poor vision on self-reported poor health and DSL on depression are new in 2004. This indicates that the influence of DSL across ages is consistent for women, while it varies for men (See Table 12).

Table 12. Multivariate regression results on DSL incidence and its influences, 2004 men.

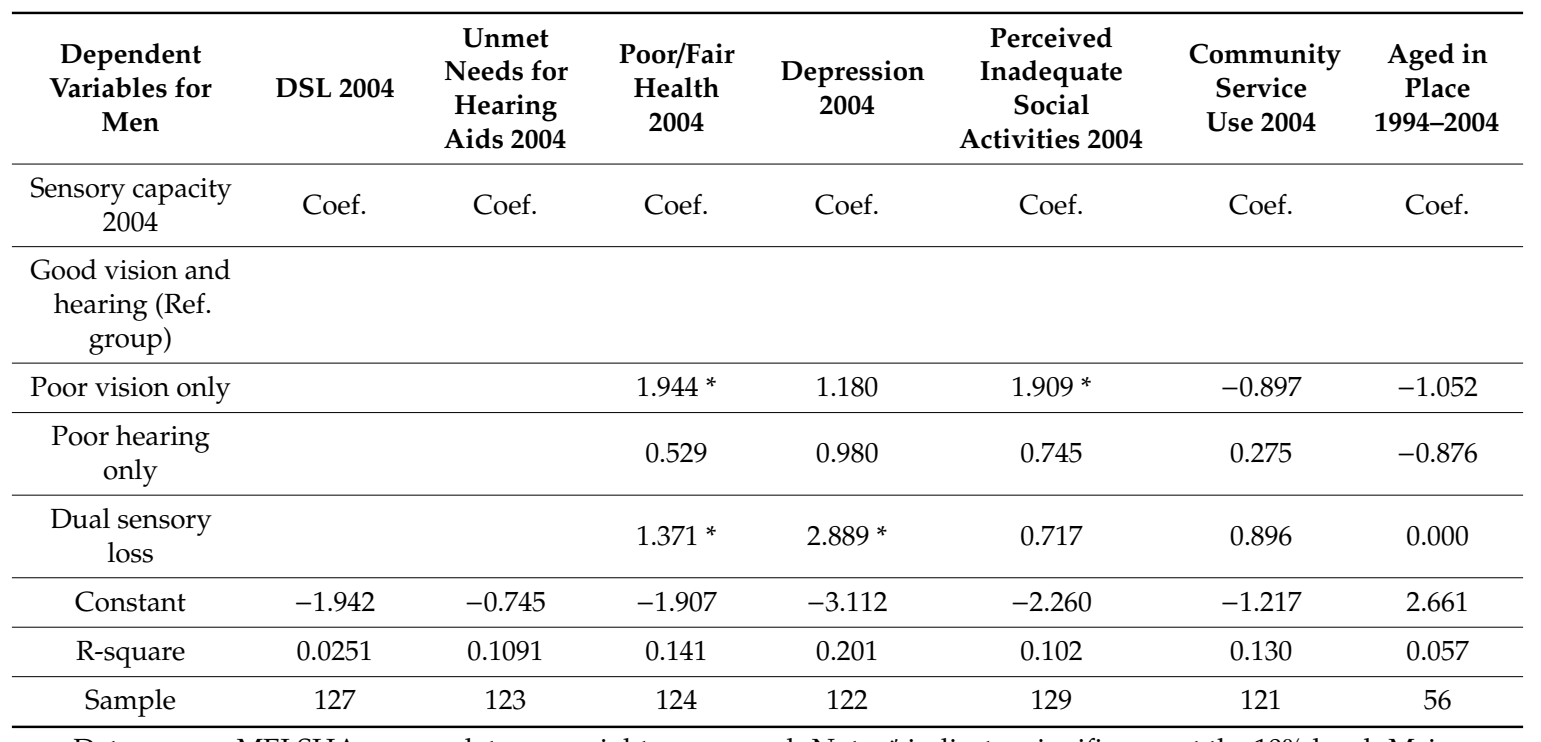

Data source: MELSHA survey data; no weights were used. Note: * indicates significance at the $10 \%$ level. Major demographics and socioeconomic status (including age group, gender, marital status, living alone, housing tenure type, main income source) are controlled for in all these regression models. The estimated coefficients from the full models are reported in Table S7. Ref group = reference group. 


\section{Discussion}

Overall, the results of this study suggested that DSL is of increasing concern when age increased for older Australians aged 65 and over, especially for Australian women who were living alone as they age. On average, older women were found to have a lower socioeconomic status (e.g., a higher proportion of living in public housing and depending on government benefits), were more likely to live alone with DSL and live longer than men. The combination of DSL with other health conditions could represent an added burden for older women.

Furthermore, more than half of the women in this study were either divorced, separated or widowed and living alone. These circumstances, combined with DSL, present women with the challenge of establishing other relationships or taking up opportunities that will differ to those women in spousal relationships. Living alone following a change in marital status or losing their partners highlights the centrality of continued connections with family, friends and community. Whilst many older women are determined to continue to engage with the world around them regardless of age or health circumstances, barriers may emerge. Engaging with other people as a single older woman and coping with DSL may prove challenging particularly when facing decreased independence and the possible threat of ill health as they age.

Good health is essential to carrying out day-to-day activities. In this study, self-rated health, depression, decreased social activity and use of community services was significantly poorer in women with DSL and confirms results of previous studies $[30,46]$. The impacts of declining physical and social health and DSL are numerous, affecting mobility, social connectedness and one's sense of well-being. These impacts are potentially further compounded for older women living alone, as is the case for the majority of older women in this study. Most aged care policy approaches aim to support people to live in their homes for as long as possible $[42,47,48]$. Our findings confirm that "poor vision only", "poor hearing only" or DSL, had no significant impact on ageing in place among older women (as well as older men) after controlling for other variables, reflecting that older women (and older men) could still age in place even if they had sensory loss. Additional support is thus required for these older women (and older men) with DSL if living at home for as long as possible is to be encouraged and upheld.

The relationship between mental health and DSL has been previously explored in a systematic review [31]. A number of studies have found a significant relationship between DSL and depressive symptoms [49-51]. The relationship between DSL and depression was confirmed in this study in that older women with DSL or poor vision or hearing had more occurrences of depression compared to older women with no sensory loss. In general, older women had a higher proportion of depression (19.3\%) when compared to older men (10.5\%); and having DSL, poor vision or poor hearing increased the likelihood of depression dramatically for women (from $12.9 \%$ to $35.6 \%, 26.7 \%$ and $22.5 \%$, respectively), whilst having poor hearing increased depression for men greatly (from $7.4 \%$ to $13.7 \%$ ). This might reflect women's role as a care giver whilst men are care receivers in later life. There have been no studies to date that have evaluated gender differences and mental health in older people with DSL even though in the general older adult population, more women than men experience depression [52].

All social and health outcomes explored in this study were generally poorer in those women with DSL, when compared to women with good hearing and vision. This suggests that older women with DSL experienced a range of health and psychosocial issues as they aged. In particular, DSL in older women was significantly correlated with poorer general health, higher occurrence of depression, less social activity and use of community services. Social activities and use of community services were significantly influenced in women with DSL or poor hearing. This could possibly be attributed to the fact that women were more likely to experience widowhood hence live alone [53].

A number of recommendations for older women are thus indicated, including the provision of programs for older women with DSL that would greatly benefit their mental health and well-being. Early detection of DSL and timely rehabilitation is important [54]. Professionals working with older women should also be aware of the combined effects of sensory loss on individuals [55] and the high prevalence of DSL in this population and its impacts. Since DSL is a multidisciplinary disorder 
often involving assessment by optometrists, opthalmologists, audiologists and otolaryngologists as well as other medical and allied health professionals, interdisciplinary collaboration in identification, assessment and management of DSL and its associations is required to ameliorate the impact of DSL in older women. Education for professionals working with older adults with DSL is warranted to ensure collaborative care is adequately provided [56].

Recently, specific interventions for people with DSL have been discussed in the literature. For example, Roets-Merken et al. [57] and Roets-Merken et al. [58] reported a protocol for a trial to examine the effectiveness of a self-management program for older people with DSL in aged care settings. Such approaches hold promise, especially since self-management approaches have been successfully implemented in older people with other chronic conditions [59]. The few studies that are available examining the effectiveness of programs for people with DSL are often poorly designed, have taken a narrow view (for example, sensory aid usage) as opposed to interventions investigating treatments leading to broader health and well-being outcomes and only few studies have delivered good rehabilitation outcomes. A review of rehabilitation interventions to improve emotional and functional status in people with sensory loss found little evidence for their effectiveness [58].

The limitations of the current study included that the survey used was representative of the older (aged 65 years and over) population in 1994 through to 2004 and in Melbourne only, not the whole of Australia. A more recent and updated survey on the ageing population covering all Australians such as the Health and Retirement Survey (HRS) in the United States (U.S.) is urgently required. In addition, participants may have responded according to their perceived social desirability of their responses, and some participants may have minimized the extent of their sensory loss for this reason. Longitudinal studies are subject to selection bias whereby participants died or were lost-to-follow up and this affects the generalizability of the results. Finally, the estimations of DSL transitions over time need to be treated cautiously due to the small sample size. Nonetheless, we estimate baseline predictors and conditional and unconditional associations between DSL and other social and health outcomes but advise caution in any attempt to interpret our results in terms of causality.

\section{Conclusions}

DSL is a significant health issue for older people that impacts on general health and well-being and the ability to engage fully in life activities. For women who live alone, this is particularly problematic. The increase in the prevalence of DSL and unmet need for hearing aids as populations age requires a concerted effort on the part of researchers and service providers to ensure that effective and efficient programs and interventions are tested and made available to older women and men with DSL.

Supplementary Materials: The following are available online at http://www.mdpi.com/1660-4601/17/1/263/s1. Table S1: Prevalence of Sensory Loss by age group for women and men in all waves from 1994 to 2004. Table S2: Persistence of DSL, hearing loss and vision loss at baseline plus 2 years, plus 6 years and plus 10 years. Table S3: Multivariate regression results for DSL prevalence and its associated outcomes in 1994 for women. Table S4: Multivariate regression results for DSL prevalence and its associated outcomes in 1994 for men. Table S5: Multivariate regression results for DSL prevalence and its associated outcomes in 1994 for men and women. Table S6: Multivariate regression results for DSL incidence and its influences in 2004 for women. Table S7: Multivariate regression results for DSL incidence and its influences in 2004 for men.

Author Contributions: Conceptualization, C.H., S.F. and C.B.; Methodology, C.H.G., C.H. and C.B.; Formal Analysis, C.H.G.; Investigation, C.B.; Writing-Original Draft Preparation, C.H., C.H.G., S.F. and C.B.; Writing-Review and Editing, C.H., C.H.G., S.F. and C.B. All authors have read and agreed to the published version of the manuscript.

Funding: This research was funded in part by the ARC Discovery project (DP160103023), and the Centre for Research on Ageing, Health and Wellbeing, Research School of Population Health, Australian National University.

Acknowledgments: The MELSHA survey was supported by the Victorian Health Promotion Foundation (grant number HSOP92) and the National Health and Medical Research Council (grant numbers 148625 and219295) and was approved by the Monash University Human Research Ethics Committee (reference number CF08/0151: 2008000047). Collaborators in earlier rounds of the survey are listed in Browning and Kendig (2010). However, the financial sponsors had no role in the design, execution, analysis and interpretation of survey data, or writing of the study. The findings and views reported in this paper are those of the authors. 
Conflicts of Interest: The authors declare no conflict of interest.

\section{References}

1. World Health Organization. Vision Impairment and Blindness. Fact Sheet. 2017. Available online: http://www.who.int/mediacentre/factsheets/fs282/en/ (accessed on 8 October 2019).

2. Taylor, H.R.; Keeffe, J.E.; Vu, H.T.; Wang, J.J.; Rochtchina, E.; Pezzullo, M.L.; Mitchell, P. Vision loss in Australia. Med. J. Aust. 2005, 182, 565-568. [CrossRef] [PubMed]

3. World Health Organization. WHO Global Estimates on Prevalence of Hearing Loss. Mortality and Burden of Diseases and Prevention of Blindness and Deafness. 2012. Available online: http://www.who.int/pbd/ deafness/WHO_GE_HL.pdf (accessed on 31 October 2019).

4. Heine, C.; Browning, C.; Cowlishaw, S.; Kendig, H. Trajectories of older adults' hearing difficulties: Examining the influence of health behaviours and social activity over 10 years. Geriatr. Gerontol. Int. 2013, 13, 911-918. [CrossRef] [PubMed]

5. World Health Organisation. Global Estimates on Prevalence of Hearing Loss. 2018. Available online: http://www.who.int/deafness/estimates/en/ (accessed on 31 June 2019).

6. Heine, C. Dual sensory loss. In Encyclopedia of Geropsychology; Pachana, N.A., Ed.; Springer: New Delhi, India, 2015; pp. 692-698.

7. Dammeyer, J. Deafblindness: A review of the literature. Scand. J. Public Health 2014, 42, 554-562. [CrossRef] [PubMed]

8. Harada, S.; Nishiwaki, Y.; Michikawa, T.; Kikuchi, Y.; Iwasawa, S.; Nakano, M.; Ishigami, A.; Saito, H.; Takebayashi, T. Gender difference in the relationships between vision and hearing impairments and negative well-being. Prev. Med. 2008, 47, 433-437. [CrossRef]

9. Schneider, J.; Gopinath, B.; McMahon, C.; Teber, E.; Leeder, S.R.; Wang, J.J.; Mitchell, P. Prevalence and 5-year incidence of dual sensory impairment in an older adult population. Ann. Epidemiol. 2012, 22, $295-301$. [CrossRef]

10. Mick, P.; Hämäläinen, A.; Kolisang, L.; Pichora-Fuller, M.K.; Phillips, N.; Guthrie, D.; Wittich, W. The prevalence of hearing and vision loss in older Canadians: An analysis of Data from the Canadian Longitudinal Study on Aging. PsyArXiv 2019. [CrossRef]

11. Heine, C.; Gong, C.H.; Browning, C. Dual Sensory Loss, Mental Health, and Wellbeing of Older Adults Living in China. Front. Public Health 2019, 7, 92. [CrossRef]

12. Bourne, R.R.A.; Jonas, J.B.; Flaxman, S.R.; Keeffe, J.; Leasher, J.; Naidoo, K.; Parodi, M.B.; Pesudovs, M.B.K.; Price, H.; White, R.A.; et al. Prevalence and causes of vision loss in high-income countries and in Eastern and Central Europe: 1990-2010. Br. J. Ophthalmol. 2014, 98, 629-638. [CrossRef]

13. West, S.K.; Munoz, B.; Rubin, G.Z.; Schein, O.D.; Bandeen-Roche, K.; Zeger, S.; German, P.S.; Fried, L.P. Function and visual impairment in a population-based study of older adults. The SEE project. Salisbury Eye Evaluation. Investig. Ophthalmol. Vis. Sci. 1997, 38, 72-82.

14. Walling, A.D.; Dickson, G.M. Hearing loss in older adults. Am. Fam. Physician 2012, 85, 1150-1156.

15. Dammeyer, J. Prevalence and aetiology of congenitally deafblind people in Denmark. Int. J. Audiol. 2010, 49, 76-82. [CrossRef] [PubMed]

16. Cruikshanks, K.J.; Nondahl, D.M.; Tweed, T.S.; Wiley, T.L.; Klein, B.E.K.; Klein, R.; Chappell, R.; Dalton, D.S.; Nash, S.D. Education, occupation, noise exposure history and the 10-yr cumulative incidence of hearing impairment in older adults. Hear. Res. 2010, 264, 3-9. [CrossRef] [PubMed]

17. Helzner, E.P.; Patel, A.I.; Pratt, S.; Sutton-Tyrrell, K.; Cauley, J.A.; Talbott, E.; Kenyon, E.; Harris, T.B.; Satterfield, S.; Ding, J.; et al. Hearing Sensitivity in Older Adults: Associations with Cardiovascular Risk Factors in the Health, Aging and Body Composition Study. J. Am. Geriatr. Soc. 2011, 59, 972-979. [CrossRef] [PubMed]

18. Pronk, M.; Deeg, D.J.H.; Smits, C.; Twisk, J.W.; Van Tilburg, J.T.G.; Festen, M.; Kramer, S.E. Hearing loss in older persons. Does the rate of decline affect psychosocial health? JAH 2014, 26, 703-723. [CrossRef] [PubMed] 
19. World Health Organization; National Institute on Aging; National Institutes of Health; Global Health and Aging; U.S. Department of Health and Human Services. Global Health and Ageing. NIH Publication No. 11-7737. 2011. Available online: http://www.who.int/ageing/publications/global_health.pdf (accessed on 2 June 2019).

20. Australian Government Productivity Commission. An Ageing Australia: Preparing for the Future. Commission Research Paper Overview, Canberra. 2013. Available online: http://www.pc.gov.au/research/ completed/ageing-australia/ageing-australia-overview.pdf (accessed on 22 January 2017).

21. Australian Government, Department of the Treasury. Australia to 2050: Future Challenges. Commonwealth of Australia, 2010. ISBN 978-0-642-74576-7. Available online: http://archive.treasury.gov.au/igr/igr2010/ Overview/pdf/IGR_2010_Overview.pdf (accessed on 22 January 2019).

22. U.S. Department of Health and Human Services. The Administration for Community Living Including the Administration on Aging. A Profile of Older Americans. Available online: https:/acl.gov/sites/default/files/ Aging\%20and\%20Disability\%20in\%20America/2017OlderAmericansProfile.pdf (accessed on 2 June 2019).

23. Australian Institute of Health and Welfare. Older Australia at a Glance. Web Report, Updates 10 September 2018, Canberra. 2018. Available online: https://www.aihw.gov.au/reports/older-people/older-australia-at-aglance/contents/summary (accessed on 19 October 2019).

24. De Vaus, D.; Qu, L. Demographics of Living Alone. Australian Institute of Family Studies, Australian Family Trends, No. 6, March 2015. Available online: https://aifs.gov.au/publications/demographics-living-alone (accessed on 22 January 2017).

25. Australian Bureau of Statistics. December 2017. 3101.0 Australian Demographic Statistics, June 2017. Available online: http://www.abs.gov.au/ausstats/abs@.nsf/0/1CD2B1952AFC5E7ACA257298000F2E76? OpenDocument (accessed on 1 March 2018).

26. Knudsen, L.V.; Öberg, M.; Nielsen, C.; Naylor, G.; Kramer, S.E. Factors influencing help seeking, hearing aid uptake, hearing aid use and satisfaction with hearing aids: A review of the literature. Trends Amplif. 2010, 14, 127-154. [CrossRef]

27. Heine, C.; Browning, C.J. Communication and psychosocial consequences of sensory loss in older adults: Overview and rehabilitation directions. Disabil. Rehabil. 2002, 24, 763-773. [CrossRef]

28. Heine, C.; Erber, N.P.; Osborn, R.; Browning, C.J. Communication perceptions of older adults with sensory loss and their communication partners: Implications for intervention. Disabil. Rehabil. 2002, 24, 356-363. [CrossRef]

29. Heine, C.; Browning, C.; Gong, C.H. Sensory loss in China: Prevalence, use of aids and impacts on social participation. Front. Public Health 2019. [CrossRef]

30. Brennan, M.; Su, Y.P.; Horowitz, A. Longitudinal associations between dual sensory impairment and everyday competence among older adults. J. Rehabil. Res. Dev. 2006, 43, 777-792. [CrossRef]

31. Heine, C.; Browning, C.J. Mental health and dual sensory loss in older adults: A systematic review. Front. Aging Neurosci. 2014, 6, 83. [CrossRef]

32. Centre for Welfare and Social Issues. The Nordic Definition of Deafblindness. 2016. Available online: http://www.kuurosokeat.fi/tiedosto/nordic_definition.pdf (accessed on 18 July 2018).

33. Heine, C.; Browning, C. Dual Sensory Loss in Older Adults: A Systematic Review. Gerontologist 2015, 55, 913-928. [CrossRef] [PubMed]

34. Mick, P.; Parfyonov, M.; Wittich, W.; Phillips, N.; Guthrie, D.; Pichora-Fuller, K.M. Associations between sensory loss and social networks, participation, support, and loneliness: Analysis of the Canadian Longitudinal Study on Aging. Can. Fam. Physician 2018, 64, e33-e41.

35. Viljanen, A.; Törmäkangas, T.; Vestergaard, S.; Andersen-Ranberg, K. Dual sensory loss and social participation in older Europeans. Eur. J. Ageing 2013, 11, 155-167. [CrossRef] [PubMed]

36. Tseng, Y.C.; Liu, S.H.; Lou, M.F.; Huang, G.S. Quality of life in older adults with sensory impairments: A systematic review. Qual. Life Res. 2018, 27, 1957-1971. [CrossRef] [PubMed]

37. Arber, S.; Davidson, K.; Ginn, J. Gender and Ageing. Changing Roles and Relationships; Open University Press: Philadelphia, PA, USA, 2003.

38. Girling, L.M.; Morgan, L.A. Older women discuss planning for future care needs: An exploratory framework. JAH 2014, 26, 724-749. [CrossRef] [PubMed]

39. World Health Organization. Women, Ageing and Health: A Framework for Action. 2007. Available online: http://www.unfpa.org/sites/default/files/pub-pdf/women_ageing.pdf (accessed on 2 June 2019). 
40. Feldman, S.; Byles, J.E.; Beaumont, R. Is anybody listening? The experience of widowhood for older Australian women. J. Women Aging 2000, 12, 155-176. [CrossRef]

41. Browning, C.; Kendig, H. Cohort Profile: The Melbourne Longitudinal Studies on Healthy Ageing Program; Oxford University Press: Oxford, UK, 2010; pp. e1-e6.

42. Kendig, H.; Gong, C.H.; Cannon, L.; Browning, C. Preferences and Predictors of Aging in Place: Longitudinal Evidence from Melbourne, Australia. J. Hous. Elder. 2017, 31, 259-271. [CrossRef]

43. Kuang, T.M.; Tsai, S.Y.; Liu, C.J.L.; Ko, Y.C.; Lee, S.M.; Chou, P. Seven-year incidence of uncorrected refractive error among an elderly Chinese population in Shihpai, Taiwan: The Shihpai Eye Study. Eye 2016, 30, 570-576. [CrossRef]

44. Yu, E.S.H.; Kean, Y.M.; Slymen, D.J.; Liu, W.T.; Zhang, M.; Katzman, R. Self-perceived health and 5-year mortality risk among the elderly in Shanghai, China. Am. J. Epidemiol. 1998, 147, 880-890. [CrossRef]

45. Lawton, M.P.; Moss, M.; Fulcomer, M.; Kleban, M.H. A research and service oriented multilevel assessment instrument. J. Gerontol. 1982, 37, 91-99. [CrossRef]

46. Crews, J.E.; Campbell, V.A. Vision impairment and hearing loss among community-dwelling older Americans: Implications for health and functioning. AJPH 2004, 94, 823-829. [CrossRef]

47. Chapin, R.; Dobbs-Kepper, D. Aging in place in assisted living: Philosophy versus policy. Gerontologist 2001, 41, 43-50. [CrossRef]

48. Scharlach, A.; Graham, C.; Lehning, A. The "Village" model: A consumer-driven approach for aging in place. Gerontologist 2012, 52, 418-427. [CrossRef]

49. Capella-McDonnall, M.E. The effects of single and dual sensory loss on symptoms of depression in the elderly. Int. J. Geriatr. Psychiatry 2005, 20, 855-861. [CrossRef]

50. Lupsakko, T.; Maija, M.; Hannu, K.; Raimo, S. Combined hearing and visual impairment and depression in a population aged 75 years and older. Int. J. Geriatr. Psychiatry 2002, 17, 808-813. [CrossRef]

51. McDonnall, M.C. Risk factors for depression among older adults with dual sensory loss. Aging Ment. Health 2009, 13, 569-576. [CrossRef]

52. National Institute of Mental Health; U.S. Department of Health and Human Services; National Institutes of Health. Depression. Available online: http://www.nimh.nih.gov/health/topics/depression/index.shtml (accessed on 24 April 2019).

53. Ogle, C.; Rubin, D.C.; Siegler, I.C. The impact of the developmental timing of trauma exposure on PTSD symptoms and psychosocial functioning among older adults. Dev. Psychol. 2013, 49, 10. [CrossRef]

54. Schneider, J.M.; McMahon, C.M.; Gopinath, B.; Kifley, A.; Barton, R.; Mitchell, P.; Leeder, S.R.; Wang, J.J. Dual sensory impairment and hearing aid use among clients attending low-vision services in Australia: The vision-hearing project. J. Aging Health 2014, 26, 231-249. [CrossRef]

55. Kiely, K.M.; Anstey, K.J.; Luszcz, M.A. Dual sensory loss and depressive symptoms: The importance of hearing, daily functioning, and activity engagement. Front. Hum. Neurosci. 2013, 7, 837. [CrossRef]

56. Fraser, S.; Southall, K.; Wittich, W. Exploring Professionals' experiences in the rehabilitation of older clients with dual-sensory impairment. Can. J. Aging 2019, 38, 481-492. [CrossRef]

57. Roets-Merken, L.M.; Graff, M.J.; Zuidema, S.U.; Hermsen, P.G.J.M.; Teerenstra, S.; Kempen, G.I.; Vernooij-dassen, M.J. Effectiveness of a self-management program for dual sensory impaired seniors in aged care settings: Study protocol for a cluster randomized controlled trial. Trials 2013, 14, 321. [CrossRef]

58. Roets-Merken, L.M.; Draskovic, I.; Zuidema, S.U.; Van Erp, W.S.; Graff, M.J.; Kempen, G.I.; Vernooij-dassen, M.J. Effectiveness of rehabilitation interventions in improving emotional and functional status in hearing or visually impaired older adults: A systematic review with meta-analyses. Clin. Rehabil. 2015, 29, 107-119. [CrossRef]

59. Bodenheimer, T.; Lorig, K.; Holman, H.; Grumbach, K. Patient self-management of chronic disease in primary care. JAMA 2002, 288, 2469-2475. [CrossRef]

(C) 2019 by the authors. Licensee MDPI, Basel, Switzerland. This article is an open access article distributed under the terms and conditions of the Creative Commons Attribution (CC BY) license (http://creativecommons.org/licenses/by/4.0/). 